\title{
Concesiones, explotación minera y conflicto en la frontera Jalisco-Colima
}

\author{
Concessions, mining and conflict \\ in the Jalisco-Colima border
}

doi: http://dx.doi.org/10.32870/

espiral.v23i67.5692

\begin{abstract}
Resumen
El presente trabajo constituye un avance del estado de la cuestión de la minería: la legislación, la producción, los beneficios $y$ las afectaciones, en particular dentro de la frontera entre Cuautitlán de García Barragán, Jalisco, y Minatitlán, Colima. El trabajo resulta relevante porque la explotación minera en México ha crecido de manera exponencial en los últimos años, $y$ tras ello ha dejado poblados enteros afectados en sus propiedades agrarias, en sus recursos naturales $y$ en sus organizaciones socioterritoriales; la incursión de estas empresas transnacionales ha dejado a su paso deforestación, tierras estériles, contaminación de agua, aire y viento. El objetivo es documentar este hecho con relación a otros, vinculado a procesos globales, lo que se ha hecho mediante la investigación de archivo, hemerográfica, cartográfica y de campo. Como resultado a este trabajo documental, se explica la situación de esta región, que abona a la situación global de México y Latinoamérica.
\end{abstract}

Palabras clave: minería, concesiones, impacto, territorio, ecología.
Hirineo Martínez Barragán•

Keywords: Mining, concessions, impact, territory, ecology.

\footnotetext{
- Profesor-Investigador del Departamento de Geografía y Ordenación Territorial de la Universidad de Guadalajara. hirineomb_2009@yahoo.com.mx.

Fecha de recepción: 27 de marzo de 2014. Fecha de aceptación: 22 de febrero de 2016.
} 


\section{Introducción'}

La minería es una de las actividades económicas de mayor tradición en México. Se practica desde la época prehispánica y fue uno de los factores de expansión regional durante la época colonial. Durante el México Independiente, la participación de la industria minera fue un factor importante para que destacara la productividad económica de algunas regiones en el país.

En fechas actuales, México es atractivo por sus recursos para inversionistas y empresarios mineros del mundo, pues es el primer productor mundial de plata, undécimo de oro y duodécimo de cobre. También es el segundo mayor productor de fluorita, el tercero más grande de bismuto y el quinto más grande de plomo. La producción minera de México, por su valor, se distribuye de la siguiente manera: $21 \%$ oro, $20 \%$ plata, $14 \%$ cobre, $8 \%$ zinc y el resto de otros minerales, según datos de la Secretaría de Economía (SE) (2013a).

Según el Anuario Estadístico de la Minería Mexicana (Secretaría de Economía, 2013a), la "minería es una pieza clave para alcanzar el crecimiento económico sostenido que el país requiere por ser un sector estratégico para la economía nacional y uno de los más dinámicos del aparato productivo" (p. 6).

En el mismo documento, se señala que para el 2012 los empleos en Jalisco aumentaron en la actividad minera, sumando en la entidad un total de 14 000. La participación de Jalisco en el valor de la producción minera se encuentra en la posición diecinueve a nivel nacional, considerando la explotación de minerales como oro, plata, cobre, plomo, barita, caolín, diatomita, dolomita, feldespato y yeso. 
Por su parte, el estado de Colima tiene la posición nueve en la producción de sustancias como fierro pellets, sal y yeso. ${ }^{2}$ Sin embargo, de los datos de este anuario se desprende que el municipio de Minatitlán, ${ }^{3}$ Colima, ocupa la tercera posición en la producción de hierro a nivel nacional (el primer lugar lo ocupa Sonora, seguido por Coahuila). Minatitlán produce el $24.04 \%$ del fierro a nivel nacional, y el $100 \%$ a nivel estatal para el caso de Colima.

No obstante, prácticamente todas las explotaciones mineras importantes registradas para Minatitlán se encuentran en la zona de indefinición jurisdiccional que existe entre los estados de Jalisco y Colima, como se verá más adelante. Esto ha propiciado que los conflictos de los lugareños por la minería y por el diferendo territorial vayan de la mano desde hace cinco o seis décadas.

Para el INEGi (2013), la minería "es una actividad económica primaria" que comprende "la exploración, explotación y aprovechamiento de minerales". Agrega que existe "una amplia variedad de minerales en la Tierra [...] la naturaleza los presenta acumulados en lugares conocidos como yacimientos, los cuales se encuentran al aire libre o en el subsuelo a diferentes niveles de profundidad". Los minerales se dividen según sus características en metálicos, no metálicos y energéticos. Los metálicos, a su vez, se clasifican en metales preciosos, metales industriales no ferrosos y metales siderúrgicos (INEGI, 2013).

En el aspecto metodológico, para la realización del presente texto, además de la revisión documental, se tuvieron como referencia las observaciones directas realizadas en campo entre 2011 y 2012, que permitieron recabar información de primera mano respecto al conflicto jurisdiccional y

2. Como parte del antecedente inmediato reciente, ver también a: Coll Hurtado y Sánchez Salazar (1999).

3. Hasta 1920, el poblado se denominó "El Mamey”. "Minatitlán” significa "lugar de minas". 
también respecto a las complicaciones que enfrentaban los lugareños de las localidades de Las Pesadas, El Platanar y Plan de Méndez en relación a la actividad minera. Así mismo, durante el año de 2013, se realizaron consultas de archivo en la Subsecretaría de Minas (perteneciente a la SE) para documentar y georeferenciar las concesiones mineras ${ }^{4}$ en esta zona. Finalmente, la información fue complementada con la revisión de documentos especializados y hemerográficos.

El presente trabajo está estructurado de la siguiente manera: primero se hace un breve recuento de la situación minera en el contexto global; luego, se exponen generalidades de la legislación que recientemente se ha emitido sobre la materia; posteriormente se precisa el área de estudio y se documentan las concesiones mineras ahí otorgadas; después se ponen en contexto las voces de los lugareños afectados por la minería; y, por último, se exponen algunas conclusiones generales.

\section{La minería en el contexto global}

Los conflictos mineros se han difundido por diversos medios impresos y electrónicos, principalmente por los daños ocasionados a la ecología o al ambiente, así como a las organizaciones territoriales y vida comunitaria de los habitantes (se recomienda ver al respecto, entre otros, los trabajos de Tetreault, 2007; Osorio, 2013; Guillén, 2009a, 2009b, 2013a y 2013b; Lagos, 2005; Estrada y Martín, 2013; Taddei, et al., 2011; González, 2013; Mendoza, 2013). Al respecto, Jorge Ceja refiere que la afectación por la "minería va más allá del saqueo de las riquezas de un país. Tiene 
consecuencias graves sobre la vida natural y cultural" (Ceja, 2014, p. 7).

El problema ecológico y la desestructuración son de las afectaciones más recurrentes tanto a nivel local como nacional e internacional, puesto que los impactos que sufren los territorios por las labores de exploración y explotación de las empresas mineras no dejan exento de daños ecológicos y socio-territoriales a ninguno de los lugares donde se llevan a cabo.

Estos daños, en mayor o menor medida, contribuyen a la contaminación y agotamiento del agua, la contaminación de suelos, el desgajamiento de cerros, la contaminación por ruido, la intrusión en zonas naturales protegidas, la explotación y el transporte clandestino de minerales, la desestructuración territorial, además de que se relacionan con amenazas a opositores, desapariciones y muertes de lugareños, según diversas investigaciones (Koch, s/f; Castro, 2013; Guillén, 2009a, 2009b, 2013a y 2013b; Arenas, 2012; Maldonado, 2015; Revista Proceso, 2013; Radio Contagio, 2013; Noticias Terra, 2013). En ese tenor, Ceja (2014, p. 1) refiere que "La globalización neoliberal en curso ha profundizado los procesos de recolonización [...] degradando a la naturaleza y acabando con las formas de vida de comunidades enteras".

Agrega Ceja que este tipo de "desarrollo se lleva de maravilla con el despojo, la profundización de la dependencia, la degradación de la naturaleza, el empobrecimiento de las mayorías, y la puesta en marcha de un capitalismo salvaje y mafioso que desprecia y desconoce los derechos de los trabajadores" (Ceja, 2014, pp. 1-2), y que en nombre del progreso se ha practicado el terrorismo de Estado y se ha criminalización a los defensores del territorio (Ceja, 2014, pp. 1-2).

En todo el mundo existen zonas que son exploradas y explotadas por los grandes consorcios mineros, principal- 
mente de origen canadiense, chino y japonés. No obstante, los principales conflictos mineros suceden en Colombia, Perú, Argentina, Brasil, Chile, Panamá, Honduras, Uruguay, Canadá, Guatemala, Bolivia, Ecuador, Costa Rica, Estados Unidos, Australia, Guyana, Papúa Nueva Guinea, Tanzania, Ghana, Filipinas y Finlandia (OCMAL, 2013).

Hacia octubre de 2013, Argentina y México compartían el segundo lugar entre una veintena de naciones mineras que afrontaban la mayor cantidad de problemas derivados de la actividad minera, cada uno de estos países con veintiséis casos, sólo superados por Perú y Chile, que contaban con treinta y tres conflictos mineros en proceso (González, 2013). La Comisión Económica para América Latina y el Caribe (CEPAL) atribuye esta situación a la falta de una legislación minera que incluya leyes ambientales, sociales, laborales y territoriales, entre otras, que sean firmes al monitorear y sancionar la falta de cumplimiento de las políticas de desarrollo sostenible de los países (González, 2013).

En México, entre los lugares donde se han generado conflictos derivados de la explotación minera se cuentan, entre otros, Tetela (en la Sierra Norte de Puebla), Chiapas, Michoacán, Baja California Sur, Querétaro, la Montaña (región de Guerrero), Valle de Ocotlán (Oaxaca), Sonora, Chihuahua, Zacatecas, Durango, la frontera Jalisco-Colima e Hidalgo. En este artículo, como se indicó al principio, se hace referencia en específico a los conflictos de una porción de territorio que incluye la frontera Jalisco-Colima.

Las empresas mineras en territorio mexicano se caracterizan por operar en forma de enclaves económicos que no promueven la diversificación de la actividad económica local ni se integran con las actividades productivas de la región; así, la economía de las localidades se ve fuertemente afectada por las fluctuaciones de la actividad minera y los ajustes que esta pueda tener en su planta laboral (García, et al., 1998). 
Para Esquivel (2013), las empresas mineras mexicanas gozan de muchos privilegios fiscales. Por ejemplo, el Grupo México, de Germán Larrea (considerado el segundo hombre más rico del mundo, después de Carlos Slim), pagó únicamente el 3.9\% de impuestos en relación a sus ventas y obtuvo 7198 millones de pesos en impuestos diferidos en 2008, según datos de la Secretaría de Hacienda y Crédito Público (SHCP) (Esquivel, 2013). Así mismo, Esquivel (2013) refiere que las mineras Frisco, de Carlos Slim, y Grupo Peñoles, de Alberto Bailleres, gozan de estímulos fiscales muy generosos por parte del Gobierno federal.

González (2013) escribió, referente a un comunicado de la CEPAL sobre la cuestión fiscal, que

los impuestos que pagaron las empresas mineras en México entre 2004 y 2012 representaron apenas al $2.9 \%$ del total de los ingresos fiscales obtenidos por el Estado, en contraste con Perú, donde han aportado $7.8 \%$, es decir 2.7 veces más [...] [a lo] que se agrega otro punto porcentual por el cobro de regalías.

Por otro lado, Jaime Martínez Veloz (Mendoza, 2013), comisionado para el diálogo con los pueblos indígenas de México, explicó que mientras que las mineras en México dejan 1.18\% en impuestos, en países como Canadá lo hacen con cerca del 18\%. Cierto que en la reforma energética se elevó al 7.5\% la tasa impositiva, pero esto sobre las utilidades netas. En este sentido, por ejemplo, los canadienses aplican su impuesto sobre utilidades brutas, y, aunque estas acciones son insuficientes, constituyen un inicio para frenar abusos.

En entrevista realizada con Hirineo Martínez, Delgado ${ }^{5}$ (2013) menciona que "simplemente la cantidad de concesiones entregadas en condiciones ventajosas para las mineras

5. Bernardino Delgado es gerente de documentación del Sistema Geológico Mexicano. 
es casi el equivalente a lo que la reforma agraria repartió tras la Revolución mexicana” en términos de extensión, aunque los beneficios sociales sean prácticamente nulos y, por tanto, altamente contrastantes respecto a la misma reforma.

Esta proporción aún puede crecer considerablemente, pues Coll Hurtado y Sánchez Salazar (1999) calcularon que hasta dos tercios del territorio nacional son favorables para la práctica de la minería. Por su parte, Guillén (2009a) refiere que, para el año de su trabajo periodístico, 10\% del territorio mexicano estaba concesionado para la exploración y explotación minera, lo que equivale a casi la superficie del estado de Chihuahua (247 $\left.938 \mathrm{~km}^{2}\right)$.

Ahora bien, independientemente de la superficie concesionada, lo más relevante es que bajo el amparo de la ley los grandes consorcios mineros han incursionado en los territorios haciendo uso y explotación de los recursos naturales protegidos por instrumentos legales que privilegian el aspecto económico por encima de la protección y conservación ecológica y social; ello, con frecuencia tratándose de la explotación minera, deja a las comunidades preexistentes sin medios de subsistencia.

Ceja (2014) refiere que los años 1992, 1993 y 1996 resultaron claves para el resurgimiento de la minería en México y sus funestas consecuencias sociales: en 1992 "se modificó el artículo 27 constitucional, dando paso a la mercantilización de las tierras ejidales y de las comunidades indígenas" (p. 5); en 1993 "se modificó la Ley Minera” (p. 5); y en 1996 "se consumaron cambios a la Ley de Inversión Extranjera, lo cual permitió que las empresas extranjeras pudiesen tener propiedades u concesiones en minas" (p. 5).

Comoquiera, la industria minera en México en los últimos años ha crecido a pasos agigantados: sólo en el Gobierno de Felipe Calderón, la inversión extranjera directa en el 
sector minero aumentó más de $224 \%$ con respecto al sexenio anterior, según cifras de la SE (Esquivel, 2013). ${ }^{6}$

Las entidades que más destacan en la actividad minera por orden de importancia y según su volumen de producción son Coahuila, Baja California Sur, Colima (por la minera Peña Colorada, entre otras que se ubican dentro de la franja de indefinición jurisdiccional), Michoacán y Zacatecas, que produjeron alrededor de $85 \%$ del volumen de la producción nacional en los últimos años.

Diez minerales, entre metálicos y no metálicos, representan $91.2 \%$ del valor de la producción nacional, y dieciocho minerales (oro, plomo, zinc, cobre, bismuto, fluorita, celestita, wollastonita, cadmio, diatomita, molibdeno, barita, grafito, sal, yeso y manganeso), de los casi cincuenta que se explotan en México, se ubican en una posición destacada, al estar entre los diez primeros lugares de la producción mundial (Instituto Nacional de Ecología, s/f).

Desde hace tiempo, México ocupa el primer lugar en la producción de plata a nivel mundial, y actualmente es el primer destino en inversión para la exploración minera en América Latina, así como el cuarto en el mundo de acuerdo con la SE y el reporte que dicha secretaría presentó publicado por Metals Economics Group, en marzo de 2013.

Además, es el quinto país con las mejores facilidades para hacer negocios mineros, de acuerdo al reporte de la consultora Behre Dolbear publicado en abril de 2013 (Ceja, 2014, p. 4); para ese mismo año, se estimaba una inversión cercana a USD 8000 millones, de acuerdo con la Cámara Minera de México (Secretaría de Economía, 2013b).

6. Desde las gestiones de los presidentes de la república Carlos Salinas de Gortari (1988-1994) y Ernesto Zedillo Ponce de León (1994-2000), se ampliaron las posibilidades para que las empresas mineras operaran en territorio mexicano, esto debido a las escasas restricciones legales y hacendarias que se les impusieron para operar. 
En cuanto al sector minero-metalúrgico en nuestro país, este contribuye con el $4.9 \%$ del producto interno bruto. En mayo de 2013, generó 337598 empleos directos y más de 1.6 millones de empleos indirectos, de acuerdo con el reporte del Instituto Mexicano del Seguro Social (IMSS), y con salarios promedio de cotización que son $37 \%$ superior al promedio nacional, conforme a cifras de la Secretaría del Trabajo y Previsión Social (STPS) hasta diciembre de 2012 (Secretaría de Economía, 2013b).

No obstante la manifiesta ganancia económica por la actividad minera, poco o nada pueden hacer los habitantes de comunidades rurales para verse beneficiados, pues la falta de capital, capacitación y relaciones les imposibilita gestionar a su favor los recursos mineros que les ofrece su territorio. Mediante algunas demandas, con mucho esfuerzo y bajo gran riesgo, han podido canalizar proyectos y programas gubernamentales en beneficio de las familias que habitan las localidades, pero han sido raquíticas, y con frecuencia nulas, las derramas económicas a nivel de localidad. En contraparte, las ganancias en casi su totalidad llegan a manos de los inversionistas de las compañías nacionales o transnacionales, cuyo único vínculo con el lugar es la extracción del mineral.

En mayo de 2013, un estudio del Foro Permanente para las Cuestiones Indígenas de la ONU abordó el reclamo de los pueblos indígenas ante la falta de cumplimiento de las autoridades de subsanar los impactos de la actividad minera, proteger sus derechos y atender sus exigencias de ser consultados antes de otorgar concesiones extractivas en su territorio.

Darcy Tetreault (2013), en su artículo "La lucha en torno a la minería en Manantlán”, refiere la inequitativa relación que existe entre empresarios y comuneros en torno a las riquezas del territorio, afectaciones a la ecología y desestruc- 
turación territorial, así como las violaciones de los derechos humanos, persecuciones y muertes.

Este es el modelo económico más común de las prácticas mineras, donde las riquezas minerales del país van a parar a manos extranjeras, dejando mínimos beneficios en comparación con los daños ecológicos ${ }^{7}$ que propicia su explotación.

Según cifras de la Dirección General de Desarrollo Minero (DGDM) (s/f), los grandes consorcios mineros que realizan exploraciones y explotaciones en nuestro país sumaban trescientos uno hasta marzo del 2012. El 70\% de las empresas (equivalente a doscientas siete) provenía de Canadá, mientras que de Estados Unidos de América provenía el $16 \%$ (cuarenta y ocho empresas).

México ocupaba el tercer lugar en empresas mineras operando en territorio nacional, con una participación del $5 \%$ (quince empresas). China sólo contaba con el 2\% (siete empresas), seguido por Australia y Japón con cinco empresas cada uno, y luego por Reino Unido, Corea e Italia, con tres, tres y dos empresas, respectivamente. Por último, se ubicaban India, Chile y Bélgica, con una empresa cada una; otras tres correspondían a sociedades entre países con una empresa cada una, en este caso Corea-México, ArgentinaItalia y México-España (ver: Gráfica 1).

En la Imagen 1, se presenta un cuadro de construcción con coordenadas numéricas para cada vértice (izquierda), y los lados, rumbos y distancias del polígono concesionado (derecha).

7. Con "daños ecológicos" se hace referencia a contaminación de agua y suelo, pérdida de especies vegetales por deforestación, así como degradación del hábitat para la fauna, entre otros daños que afectan a las condiciones "normales" de la naturaleza y la sociedad. 
Imagen 1. Construcción de coordenadas por vértice $y$ datos de polígono concesionado

\begin{tabular}{|c|c|c|}
\hline & & \\
\hline \multicolumn{2}{|c|}{ COORDENADAS } & \\
\hline NORTE & ESTE & PUNTO \\
\hline 2144758.92 & $597,434.41$ & \\
\hline $2,146,486.46$ & $597,403.83$ & P.P.M. \\
\hline $2,146,850.02$ & $597,403.83$ & $\mathbf{1}$ \\
\hline & & \\
\hline $2,146,850.02$ & $597,182.99$ & $\mathbf{2}$ \\
\hline $2,146,758.92$ & $597,182.99$ & $\mathbf{3}$ \\
\hline $2,146,758.92$ & $596,934.41$ & $\mathbf{4}$ \\
\hline $2,145,758.92$ & $597,182.99$ & $\mathbf{5}$ \\
\hline $2,145,758.92$ & $595,834.41$ & $\mathbf{6}$ \\
\hline $2,145,750.02$ & $597,182.99$ & $\mathbf{7}$ \\
\hline $2,145,750.02$ & $595,782.99$ & $\mathbf{8}$ \\
\hline $2,147,750.02$ & $597,182.99$ & $\mathbf{9}$ \\
\hline $2,147,750.02$ & $598,782.99$ & 10 \\
\hline $2,146,850.02$ & $597,182.99$ & $\mathbf{1 1}$ \\
\hline
\end{tabular}

\begin{tabular}{|c|c|c|c|}
\hline \multirow{2}{*}{\multicolumn{4}{|c|}{$\begin{array}{l}\text { Datos del Lo } \\
\text { Linea Auxil } \\
\text { Perímetro }\end{array}$}} \\
\hline & & & \\
\hline Lados & Rumbos & Distancias & Colindancias \\
\hline 120 & Deste & $500.00 \mathrm{mts}$. & Minatitlan Exp 102/0173 \\
\hline 23 & Norte & $387.18 \mathrm{~ms}$. & Terreno Libre \\
\hline 34 & Este & $700.00 \mathrm{mts}$. & Terreno Libre \\
\hline 45 & Surt & 200.00 mts. & Terreno Libre \\
\hline 56 & Este & 70000 mts. & Terreno Libre \\
\hline 67 & Sur & $700.00 . \mathrm{mts}$ & Terreno Libre \\
\hline 78 & Oeste & $500.00 \mathrm{mts}$ & Terreno Libre \\
\hline 89 & Norte & $512.82 \mathrm{mts}$. & Terreno Libre \\
\hline 91 & Oeste & $400.00 \mathrm{mts}$ & Minatitlan Exp. 102/0173 \\
\hline
\end{tabular}

Fuente: fotografías tomadas en investigación de campo de los archivos del Sistema de Administración Minera (SIAM). Guadalajara, Jalisco, México. Secretaría de Economía (2013a).

Gráfica 1. Origen de las empresas mineras en México

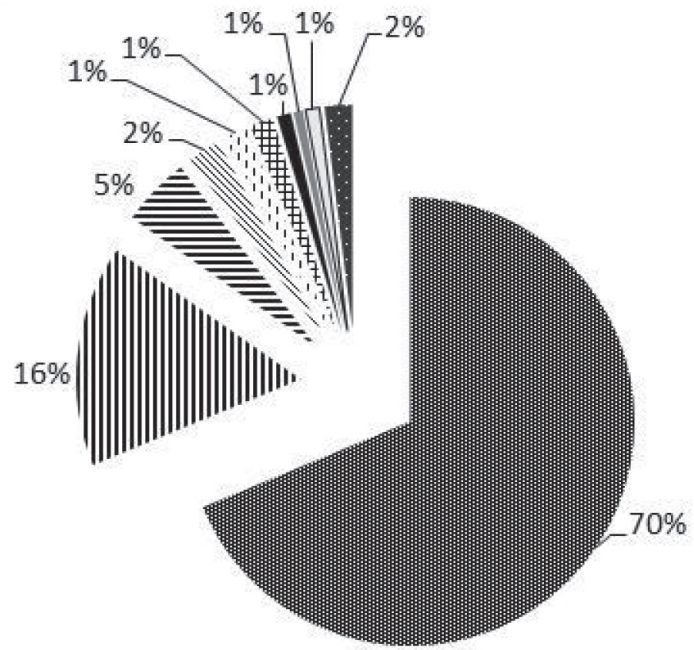

聞 Canadá

III USA

= México

$\approx$ China

:' Australia

\# Japón

- UK

Italia

Corea

Otros

Fuente: elaboración propia con base en Secretaría de Economía (2013b). 
Respecto a la actividad empresarial de la minería y lo permisivo del Gobierno mexicano, Jesús Estrada y Rubén Martín, conductores del programa "Cosa pública", de Radio Metrópoli, el jueves 9 de mayo de 2013 comentaban:

[...] el tema de las explotaciones mineras es uno de los grandes robos que tenemos los mexicanos en este momento. Son concesiones que se detonaron: si bien existieron en la Colonia, se deprimió esta actividad durante una buena parte del siglo XX, pero a partir de hace unos diez o doce años volvieron a crecer las concesiones que el Gobierno federal entregaba a particulares [...], muchos mexicanos, pero la mayoría extranjeros, $75 \%$ de las empresas que trabajan en México son extranjeras, la mayoría son canadienses. Más de una cuarta parte del territorio de Jalisco está entregado a concesiones mineras, más de un tercio del territorio de todo el país está entregado a concesiones mineras y son unas condiciones de explotación... no se puede decir de otra manera, por eso digo que es uno de los grandes robos en este momento, porque, de acuerdo a la actual legislación, una empresa minera solamente está obligada a pagar en derechos, entre MXN II O, MXN III y MXN I75 al semestre por explotar lo que ahí se encuentre, $y$ una de las constantes del negocio minero es que mete divisiones en las comunidades porque sobornan autoridades (Estrada y Martín, 2013).

De acuerdo con el suplemento informativo La Jornada del Campo, hasta agosto de 2012 existían en el país 27211 concesiones mineras, lo que representaba una superficie territorial de aproximadamente $31000000 \mathrm{~h}$, es decir, el 16.1\% del territorio nacional (Llano, 2014). Según la DGDM, en Jalisco se otorgaron, de los años 2000 a 2009, 1290 concesiones mineras, que abarcaban $1272740 \mathrm{~h}$, esto equivale aproximadamente al 21.5\% de los 80137 kilómetros (8 000000 h) que comprende el territorio estatal; según la SE, las com- 
pañías mineras abarcaban el 33\% del territorio jalisciense (Secretaría de Economía, 2013a). ${ }^{8}$

Ante los reclamos de comunidades enteras por las afectaciones ecológicas y socio-territoriales, el Gobierno mexicano justifica los hechos nocivos en función de las cifras macroeconómicas, y en razón de ello otorga poca importancia a los impactos que afectan a lugares específicos, dando mayor valor a los beneficios económicos aportados al producto interno bruto derivados del sector minero (Guillén, 2009a).

\section{La legislación minera mexicana}

Para este sucinto recuento e interpretación, se debe decir que el artículo 27 constitucional, desde la promulgación de la Constitución Política de los Estados Unidos Mexicanos, en 1917, establecía el dominio de la nación sobre los recursos minerales del subsuelo, dando oportunidad a particulares mediante concesiones para que extrajeran esos recursos.

Siendo presidente Lázaro Cárdenas del Río (19341940), se promulgó una reforma energética que dejaba bajo propiedad única y exclusiva del Estado mexicano los recursos mineros y energéticos; con la nueva legislación, se suprimían las concesiones de explotación del petróleo y los hidrocarburos a particulares. En noviembre de 1940, fueron refrendados los derechos exclusivos del Estado para explotar los recursos de hidrocarburos, pero se anexó una ley reglamentaria al artículo 27 constitucional, en la cual se concedían contratos a particulares para hacer este tipo de explotación sin poner en riesgo los derechos de la nación, en el siguiente sentido:

8. Estas se concentran principalmente en las regiones Valles, Sierra de Amula, Sur y Costa, en áreas que presentan menos densidad de población y actividad económica de baja rentabilidad. Aunque sus prácticas extractivas generalmente se producen en terrenos "remotos" alejados de las ciudades, los pequeños poblados que habitan la zona sufren en su totalidad los efectos nocivos de esta práctica.

\section{8}


El Ejecutivo, al formular la iniciativa que culminó con la reforma constitucional de que se trata, y después en diversas declaraciones, ha expresado su punto de vista de que la exclusión de los particulares del régimen de concesiones que el artículo 27 fija para la explotación de los recursos naturales del dominio público no implica que la nación abandone la posibilidad de admitir la colaboración de la iniciativa privada, sino simplemente que esa colaboración deberá realizarse en el futuro dentro de las formas jurídicas diversas de la concesión [...] (Diario de los Debates, 1939, s/p).

Posteriormente, hubo otras modificaciones al artículo 27 constitucional en 1958, 1960 y 1983, pero fue en 1993 cuando se aprobó una nueva Ley Minera, la cual consideraba a esta actividad como de utilidad pública y preferente. Esta reforma, junto con la reforma agraria de un año anterior, permitió legalmente la privatización de las propiedades tanto de ejidos como comunidades agrarias, abrieron el espacio legal para que las empresas mineras nacionales y extranjeras se expandieran por todo el territorio nacional, y con muy pocas restricciones. De aquí, como ya se dijo, el acelerado resurgimiento de la minería en nuestro país.

Con la nueva reforma energética, presentada por el actual presidente (Enrique Peña Nieto), aprobada por el Senado el 11 de diciembre de 2013, promulgada por el Ejecutivo el 20 de diciembre de ese mismo año y publicada al día siguiente en el Diario Oficial de la Federación, se han hecho modificaciones al mismo artículo 27 y al artículo 28 que aluden al tema de las concesiones, relacionado a los hidrocarburos y al petróleo, así como a la electricidad, aparentemente sin afectar al sector minero.

Sin embargo, en la reforma hacendaria aprobada por el Senado de la república en octubre de 2013 también se hacían cambios a la Ley Federal de Derechos, con los cuales se aprobaba fijar un impuesto de $7.5 \%$ a ganancias de empresas mineras, ajustándose la distribución de los nuevos derechos 
mineros en el siguiente sentido: que el 50\% se destinara a los municipios donde se asientan las minas, el 30\% a los Gobiernos estatales, y el 20\% a la federación (García, 2013).

Respecto a las reformas de 2013, aún no se tienen evidencias que permitan valorar los resultados, pero empresarios de diversos sectores manifestaron su descontento en relación a la reforma hacendaria del 8 de septiembre de 2013. Argumentaban que este gravamen a las ganancias de la minería perjudicaría al sector productivo, quien, decían, es el que invierte, mueve la economía y crea empleos. Sentenciaban que con ello ya nadie querría invertir en México (Acosta Córdova, 2013).

En cuanto a la conformación, exploración y explotación de concesiones mineras, ${ }^{9}$ es importante conocer con mayor detalle la Ley Minera para la mejor interpretación de aspectos ecológicos, empresariales, sociales y políticos. Dicha ley fue publicada en el Diario Oficial de la Federación el 26 de junio de 1992, siendo presidente de la república Carlos Salinas de Gortari. Con posterioridad se han producido algunas reformas, la más importante en el año de 2006.

La aplicación de esta ley corresponde al Ejecutivo federal por conducto de la Secretaría de Economía, y es de orden público para todo el territorio nacional. En este sentido, la ley, en el artículo 2, señala que "se sujetarán a las disposiciones [...] la exploración, explotación, y beneficio de los minerales o sustancias que en vetas, mantos, masas o yacimientos constituyan depósitos cuya naturaleza sea

9. Por exploración se entienden las obras y trabajos realizados en el terreno con el objeto de identificar depósitos de minerales o sustancias, al igual que de cuantificar y evaluar las reservas económicamente aprovechables que contengan. Por explotación se entienden las obras y trabajos destinados a la preparación y desarrollo del área que comprende el depósito mineral, así como los encaminados a desprender y extraer los productos minerales o sustancias existentes en el mismo. Esto según la Ley Minera, publicada en el Diario Oficial de la Federación el 26 de junio de 1992. Ultima reforma publicada el 26 de junio de 2006. 
distinta de los componentes de los terrenos" (Diario Oficial de la Federación, 1992, p. 1).

Entre las actividades que realiza la SE en relación con la Ley Minera, en su artículo $7^{\circ}$ se señalan las siguientes: a) regular y promover la exploración y explotación, al igual que el aprovechamiento racional y preservación de los recursos minerales; b) elaborar y dar seguimiento al programa sectorial en materia minera; c) someter proyectos de decreto para determinar la concesión de minerales o sustancias; d) expedir títulos de concesión y de asignación minera, al igual que resolver sobre su nulidad o cancelación, o la suspensión e insubsistencia de los derechos que deriven de las mismas; e) integrar el expediente y resolver en los términos de la ley; f) solicitar y recibir información sobre la producción, beneficio y destino de los minerales; g) llevar el Registro Público de Minería y la Cartografía Minera.

A pesar de que la Ley Minera es enfática al mencionar que la exploración y explotación de minerales o sustancias sólo podrá realizarse por personas físicas de nacionalidad mexicana, ejidos y comunidades agrarias, pueblos y comunidades indígenas, las empresas y capitales extranjeros han encontrado la forma de apropiarse de estos bienes nacionales mediante la figura de prestanombres, con la aparente complacencia de las autoridades.

Esta ley hace referencia a que para ser titular de concesiones mineras se deben cumplir una serie de requisitos, entre los que se encuentran: que el titular o sociedad tenga su domicilio legal en la república mexicana, y que la participación de inversionistas extranjeros se ajuste a las disposiciones de la Ley Minera.

Asimismo, en dicha ley se pueden encontrar los requisitos técnicos que los peritos en minería requieren para completar los requerimientos solicitados por la Secretaría de Economía 
en sus denuncios. ${ }^{10}$ Es importante señalar, además, que las concesiones mineras tienen una duración de cincuenta años, contados a partir de la fecha de su inscripción en el Registro Público de Minería, los cuales se prorrogarán por igual término si sus titulares no incurrieron en las causales de cancelación (Diario Oficial de la Federación, 1992, p. 11).

La minería, desde la época de la Colonia, ha jugado un papel importante en la configuración de los territorios, como la construcción de caminos y la ubicación de grandes asentamientos humanos. Así mismo, su incidencia en la economía ha propiciado grandes cambios en la vida de los habitantes cercanos al lugar.

Ahora bien, las valoraciones sobre los impactos (positivos/negativos) suelen ser muy distintas si se hacen desde lo local, lo nacional o lo global; en lo que a este trabajo respecta, los cambios propiciados por la actividad minera han sido más bien en detrimento de la calidad de vida de las poblaciones, pues no se aprecia el desarrollo comunitario en función de dicha actividad: a cambio de un empleo asalariado o mejor infraestructura, se presentan muchas otras externalidades que afectan negativamente la calidad de vida de los lugareños.

\section{El área de estudio}

El territorio de referencia para este estudio de caso comprende parte de la zona de indefinición territorial de los estados de Jalisco y Colima, en la colindancia de los municipios de Cuautitlán de García Barragán, Jalisco, y Minatitlán, Colima. Para ilustrar más ampliamente la situación, se tomaron como referencia las concesiones otorgadas dentro de la carta topográfica denominada "Minatitlán", escala 1:50 000, clave E13-B33 del INEGI, cuya área se define por 
las coordenadas métricas (UTM) extremas 570 000-605 000 metros latitud norte y 2128 500-2 156150 metros de longitud oeste, la cual forma un rectángulo que comprende 96775 h (ver: Imagen 2).

Imagen 2. Mapa de concesiones según su condición

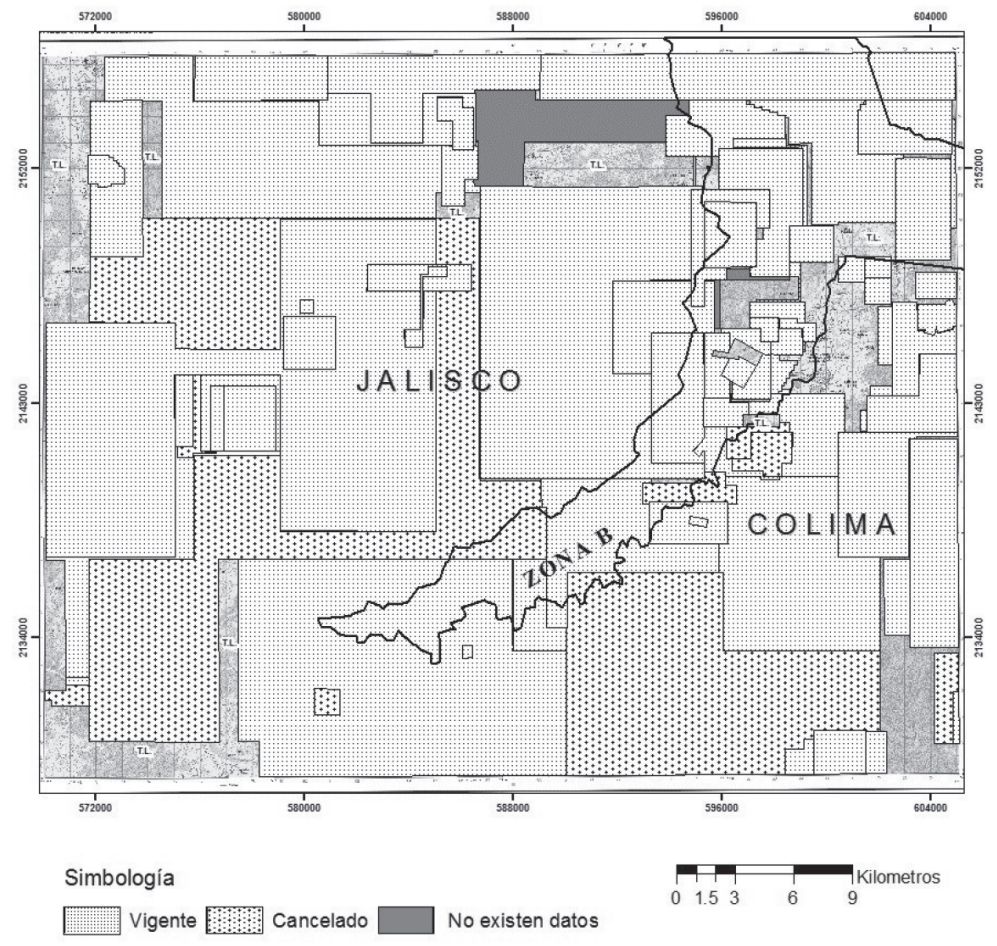

Fuente: elaboración propia con base en INEGI (2001).

Para llegar a la zona desde la ciudad de Guadalajara, existen dos vías: la primera rumbo a la ciudad de Colima y de ahí rumbo al poblado de Minatitlán; la segunda es por la "carretera a Barra de Navidad, pasar por la ciudad de Autlán de la Grana y antes de llegar a la cabecera municipal de La Huerta tomar la carretera estatal hasta llegar a 
la cabecera municipal de Cuautitlán de García Barragán” (entrevista personal, 2011).

Desde las respectivas cabeceras municipales se puede llegar a distintos lugares de la zona de estudio, ya sean asentamientos humanos o centros de explotación minera, por caminos y terracerías, en su mayoría de mala calidad. Así, por ejemplo, el recorrido "Desde Cuautitlán hasta Minatitlán pasando por Ayotitlán y Telcruz [es de] setenta kilómetros a una velocidad promedio de cincuenta kilómetros por hora" (Urzúa Soto, 2013, p. 15). Este camino de oriente a poniente y otro que se desprende hacia el sur rumbo a Chacala son los que unen espacialmente el territorio de esta zona.

El territorio de referencia comprende varios conjuntos montañosos denominados localmente "Sierra de Manantlán", "Sierra del Perote" y "Sierra el Mam ey", los cuales forman parte de la Sierra Madre del Sur. En este territorio montañoso se encuentra una de las reservas de fierro más grande del país, pero también, en colindancia por el rumbo norte, se ubica la reserva de la biósfera Sierra de Manantlán, ${ }^{11}$ con 139577 h, dentro de los municipio de Autlán, Cuautitlán, Casimiro Castillo, Tolimán y Tuxcacuesco, en el estado de Jalisco, así como Minatitlán y Comala, en el estado de Colima. Estos dos usos resultan incompatibles para un mismo territorio, lo que ha detonado reclamos por invasión a zonas protegidas.

Dentro de este rectángulo de 35 por 27.65 kilómetros, se ubica parcialmente la zona $B$ del conflicto jurisdiccional correspondiente a la controversia constitucional $3 / 98 .{ }^{12}$ Esta

II. Creada por decreto del 23 de marzo de 1987. El decreto como "reserva de la biósfera" se promovió, a raíz del descubrimiento del teocintle, "zea diploperennis", planta con gran potencial para el mejoramiento genético del maíz, en 1979. Desde entonces, investigadores de la Universidad de Guadalajara y la Universidad de Wisconsin-Madison realizan ahí estudios.

12. Las controversia constitucional $3 / 98$ señalaba tres zonas de disputa territorial: zona A, en la costa entre Cihuatlán, Jalisco, y Manzanillo, Colima, que comprendía 
zona, como lo señaló Urzúa Soto (2013), cobró importancia en materia minera desde la década de 1980, luego de que se intensificaron las explotaciones por diversas empresas, en particular la llamada "Consorcio Minero Benito Juárez Peña Colorada, S. A. DE C. V.”, pues desde entonces se manifestaron incompatibilidades entre los modos de explotación minera a cielo abierto y las prácticas agropecuarias, de caza y de recolección que tradicionalmente realizaban los lugareños. Además, por su cercanía, los márgenes o áreas de amortiguamiento de la reserva de la biósfera de la Sierra de Manantlán están siendo profundamente alterados (Urzúa Soto, 2013).

Las localidades más importantes ubicadas en el lugar de estudio son Minatitlán y Paticajo, en el estado de Colima, con 4588 y setecientos dieciocho habitantes, respectivamente y según el censo poblacional de 2010. Del lado de Jalisco, los asentamientos más poblados son Telcruz, Chacala, Cuzapala y Ayotitlán, con 1 252, 1 024, ochocientos setenta y setecientos cuatro habitantes, respectivamente.

Las principales localidades ubicadas dentro la zona B, que consiste en una parcialidad de la zona de estudio, como se puede apreciar en la Imagen 2, son Benito Juárez Peña Colorada, Las Pesadas, El Platanar y Plan de Méndez, con novecientos dieciocho, setenta y dos, ciento sesenta y cuatro, y ciento sesenta y un habitantes, respectivamente. El total de localidades dentro del territorio de estudio es de ciento cuarenta y uno, según el censo de 2010, las cuales suman 20307 habitantes, con una densidad promedio de veintiún habitantes por kilómetro cuadrado. Para tener un punto de referencia, considérese que la densidad promedio de Jalisco

I 5 I00 h; la zona B, en la Sierra El Mamey, entre Minatitlán, Colima, y Cuautitlán, Jalisco, que comprendía 20937 h; y la zona C, en las faldas del volcán Colima, entre los municipios de Comala, Colima, y Zapotitlán de Vadillo, Jalisco, que comprendía 4647 h (Martínez Barragán y Moreno Cervantes, 200I). 
es de noventa y cuatro habitantes por kilómetro cuadrado, mientras que para Colima es de ciento dieciséis.

\section{Las concesiones mineras}

Para desarrollar este apartado, se tomó como fuente principal el archivo de la Subsecretaría de Minas, adscrita a la SE, en la delegación de Jalisco, con sede en la ciudad de Guadalajara. Las tareas de consulta se realizaron entre el 29 de julio y el 25 de octubre de 2013 , y los resultados constituyen la base de los datos aquí referidos, que corresponden a las concesiones otorgadas en el territorio de referencia, tanto vigentes como canceladas, las cuales cubren un lapso de 1993 a octubre de $2013 .^{13}$

Metodológicamente, es importante señalar el principio y fin del trabajo de archivo (julio-octubre, 2013) porque los denuncios ${ }^{14}$ de lotes mineros y su registro son muy dinámicos, incluidas las cancelaciones, lo que propicia constantes cambios (altas y bajas). Además, la cartografía del SIAM no cuenta con actualizaciones constantes en sus bases de datos.

La manera más confiable de obtener información de las concesiones y el estado que guardan es combinando: 1) la revisión de cartas topográficas escala 1:50 000, donde se deben señalar manualmente las concesiones mineras inscritas, para de ahí revisar el expediente de cada concesión; 2) la obtención de los polígonos y bases de datos digitales de la carta topográfica escala 1:50 000 con la información de

13. Es importante plantear, a manera de hipótesis, que todas las concesiones mineras encontradas tienen vigencia a partir de 1993, en razón de que fueron actualizadas a partir de las reformas a la Ley Minera, antes comentadas. La concesión minera con mayor antigüedad es la llamada "Agrupamiento Rincón II", del 6 de agosto de 1993, aunque obviamente existían minas en operación que renovaron su concesión con posterioridad.

14. Entiéndase por "denuncio" la solicitud que se hace ante las autoridades de un territorio para exploración y explotación minera, esto según comentó en conversación personal el encargado del archivo en la Subsecretaría de Minas.

\section{6}


predios mineros (cada una con un costo de MXN 3 000.00); y 3) la revisión de la cartografía emitida por el SIAM en la página electrónica oficial de la SE.

No obstante lo minucioso del trabajo, quedaron dos tareas pendientes: confrontar la información en campo y entrevistar a los propietarios o representantes, tareas que darían mayor actualidad y veracidad a la información recabada, pero que rebasaron las posibilidades en esta etapa de la investigación.

Durante la consulta de archivo, en una primera aproximación se observó que, en términos generales, los expedientes tienen la misma estructura, en apego a la Ley Minera respecto a la organización de información. Para solicitar la consulta de expedientes en la Subsecretaría de Minas debe conocerse el número y nombre de concesión, asimismo, para agilizar y facilitar el servicio otorgado, previamente se debe llenar un formato donde se especifique el tipo de información que se requiere, ya sea cartográfica o en expediente. ${ }^{15}$

La conformación de cada expediente está organizada de la siguiente manera: en la portada de la carpeta se encuentra información del nombre de la concesión, número de expediente, y en algunos casos fecha de apertura y vigencia documental. En su interior, cuenta con un croquis de polígono o lote, el cual contiene vértices, los lotes mineros colindantes, distancias entre vértices, superficie, puntos de partida y de control. Incluye también el oficio donde se remiten los trabajos periciales del lote minero que se indica, con el siguiente contenido: datos generales de la mina, motivo de trabajo, análisis preliminar, reconocimiento, punto de control, trabajos realizados, punto de partida, perito minero y cuadro de construcción con las coordenadas (ver: Imágen 1).

I5. El formato para solicitar información sobre una concesión minera lo proporciona la Subsecretaría de Minas. 
También incluye fotografías de la mojonera, la cual contiene datos gravados del nombre del lote, la agencia y superficie.

El registro de coordenadas (Imagen 1), se ha hecho de dos formas distintas para referir los vértices de cada uno de los polígonos mineros. Una forma ha sido mediante coordenadas de cada vértice ("X" y "Y"), y otra mediante rumbos y distancias. Ambas constituyen el polígono de construcción que comprende la superficie otorgada en forma de concesión. La mayoría de los expedientes revisados contiene información de los vértices mediante rumbos y distancias; en este caso, el punto de partida de cada polígono es el único que cuenta con coordenadas.

En Jalisco, según la SE (2013b), se tiene registrados aproximadamente 1847 denuncios de lotes mineros titulados, de los cuales trescientos tres están cancelados (Delgado, 2013). En los municipios de Cuautitlán, Jalisco, y Minatitlán, Colima, se tienen, según el SIAM, treinta y una y cincuenta concesiones mineras, respectivamente, sin incluir las de otros municipios; todas tiene registro posterior a 1993. El año con mayores registros fue 2007, y el de menor número fue 1996 (ver: Gráfica 2).

Gráfica 2. Concesiones mineras por año

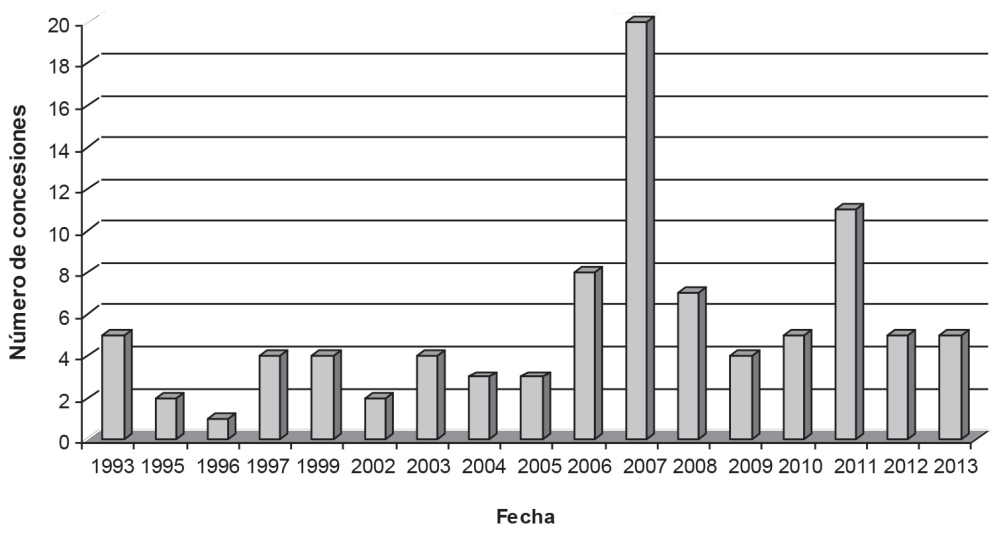

Fuente: elaboración propia con base en trabajo de campo. 
Mediante el trabajo de archivo, se detectaron noventa y un lotes concesionados dentro del área de estudio, de los cuales setenta contaban con expediente, mientras que los veintiuno restantes tenían su expediente extraviado. Se incluyeron denuncios hechos para los municipios de Cuautitlán y Minatitlán, así como para sus colindantes municipales dentro de la "carta" de referencia: Casimiro Castillo, Tolimán, Villa de Álvarez, Manzanillo y Coquimatlán (ver: Gráfica 3).

Gráfica 3. Concesiones mineras en la zona de estudio

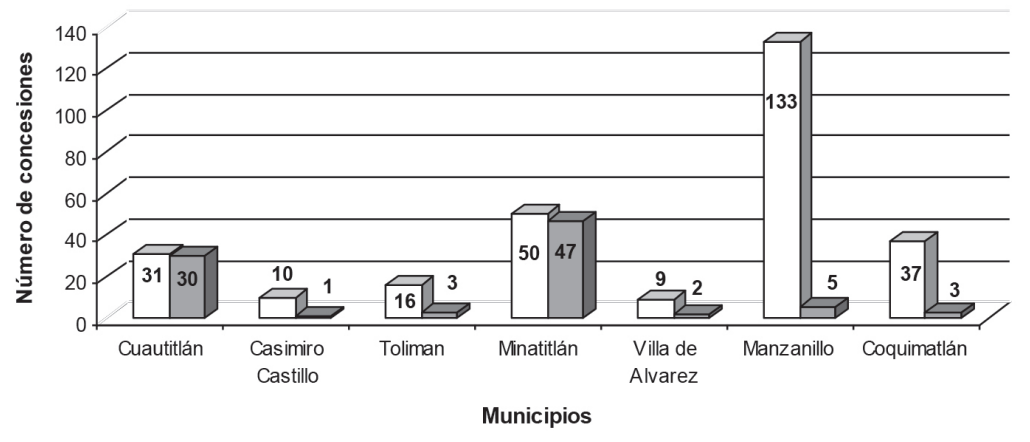

$\square$ No. Concesiones Mineras por Municipio según el SIAM $\square$ Conseciones ubicadas en la carta E13B33

Fuente: elaboración propia con base en trabajo de campo.

También se detectaron once lotes que fueron denunciados, pero no concesionados; las razones principales fueron errores de peritaje. Asimismo, en el expediente de cuatro lotes concesionados la información resultó insuficiente para georeferenciar los respectivos polígonos: Minatitlán, Pillipao 2, El Pesar y Chachalaca. Por tanto, en el mapa no están referidas estas concesiones.

Otra variante es que de las noventa y un concesiones mineras en toda el área de estudio, setenta y ocho de ellas están en condición "vigente" y diez se encuentran "canceladas"; además, tres de ellas no tienen dato al respecto (ver: 
Imagen 2). ${ }^{16}$ De esas noventa y una, cincuenta y siete se encuentran registradas para el estado de Colima y treinta y cuatro para Jalisco.

La extensión de las concesiones es muy variada: van desde las 11306.1089 h, en el lote llamado La Gallina, hasta las 14463.70 h, en el lote llamado "Gan-Bo" (el cual está cancelado porque a partir de una controversia con lugareños y ejidatarios se determinó que contaminaba los mantos freáticos y aguas superficiales -Ferrer, 2013-). En contraste, se detectaron lotes tan pequeños como el de La Huasteca Fracc. II, con apenas 0.0663 h $\left(663 \mathrm{~m}^{2}\right)$.

Cabe señalar que de las $96775 \mathrm{~h}^{17}$ correspondientes al área de estudio, 87814 están concesionadas (aunque algunas en calidad de "canceladas"), lo cual equivale al $90.7 \%$ del total de la superficie que comprende la carta de referencia. En lo que respecta al área en disputa jurisdiccional que parcialmente comprende la zona B, 12683 hectáreas (89\%) están concesionadas y sólo 1420 hectáreas (11\%) están sin concesionar. Esto explica por qué el conflicto socio-territorial entre los habitantes y los empresarios mineros en la zona se ha agudizado tanto en las últimas dos décadas.

Durante el análisis de los expedientes se pudo advertir, además, que en determinadas zonas se repite el mismo solicitante (persona o empresas), que participa para distintas concesiones. Entre las empresas que tienen más concesiones se encuentran: Consorcio Minero Benito Juárez Peña Colorada, S. A. de C. V. (subsidiaria de dos empresas, Mittal Steel, de la India, e Hylsa Ternium, de capital argentino-italiano),

16. La superficie se obtuvo teniendo en consideración los valores extremos de las coordenadas, las cuales definen un rectángulo de aproximadamente 27.65 por 35 kilómetros.

17. En relación a la cuantificación cartográfica, se geo-referenciaron todas las concesiones que se ubican en la carta topográfica El3B33, de lo cual algunos polígonos, como el Cascaronal 2, Deysi, Unificación el Artillero, Gan-Bo o Estrella del Ser II, trascienden el área determinada, por lo que se realizó un recorte para sólo considerar las proporciones que hay en el área de estudio. 
Minera del Norte, S. A. de C. V. (antes Minera Monterrey, de capital mexicano), Exploraciones Mineras Parreña, S. A. de C. V. (de capital mexicano), Chapultepec Mining Corporation, S. A. de C. V. (de origen canadiense), Desarrollo Minero Unificado de México, S. A. de C. V. (subsidiaria de la empresa china Tianjin Binhai Harbor Port Group Co.), Grupo Zakamura (de capital chino), Industria Minera de México, S. A. de C. V. (subsidiaria de Grupo México), Gan-Bo Minera Internacional y Cía., S. A. de C. V. (de origen chino) y Minera El Mamey, S. A. de C. V. (subsidiaria de AHMSA, de capital mexicano, privatizada en 1992).

Así mismo, también se pudo observar que algunos particulares han solicitado concesión en varias ocasiones, y a veces acompañados de otro solicitante o "socio", como se le nombra dentro de la Subsecretaría de Minas. Entre los solicitantes más recurrentes se encuentran los siguientes: J. Adolfo Jiménez Vargas, ocasionalmente en sociedad con Ignacio González Zamora; Manuel Meza Díaz, en sociedad con Jesús Fernando Fernández, entre otros con dos o más participaciones. Estos particulares, en general, son buscadores de yacimientos, los cuales denuncian y después venden o rentan sus derechos a empresas dedicadas a la explotación minera.

En los expedientes también se señala el porcentaje que tendrá cada socio, en caso de ser más de uno el denunciante. En las empresas por lo regular el porcentaje de ganancias es del 100\%. En el caso de particulares, se reparten los porcentajes de ganancia entre el número de socios de manera proporcional a su participación.

Los buscadores de minas, como primera aproximación, exploran el territorio para conocer qué tipo de yacimiento existe en la zona, apoyándose con mapas e imágenes de satélite, lo cual complementan con la opinión teórica de un geólogo, la observación en campo y la recolección de muestras para determinar en laboratorio. En el caso de la zona de estudio, 
las principales explotaciones de sustancias mineras en los lotes concesionados son de oro, plata, hierro, cobre, plomo, caolín, dolomita, y, en menor proporción, de molibdeno, tungsteno, zinc, y manganeso. También se concesionaron varios predios para que se pudiera explotar toda sustancia concesible (TSC).

Por lo general, la explotación minera se realiza de dos maneras: minas a cielo abierto y minas subterráneas. La primera se hace con maquinaria de grandes proporciones sobre la superficie del terreno; la segunda, como su nombre lo indica, se efectúa debajo de la superficie, y por lo regular es con trabajo manual y maquinaria pequeña, ya que la maquinaria grande no tiene suficiente accesibilidad. En la zona de estudio domina la primera, y por la remoción de grandes cantidades de material (principalmente descapote) no sólo afecta el lugar donde se realiza la explotación, sino también las áreas de tiraderos o confinamiento.

\section{Los impactos de la minería}

En diversos lugares del mundo se elevan voces de grupos organizados que se oponen a la instalación en su territorio de empresas mineras, con el argumento principal de que deterioran el medio ambiente. La práctica de la minería históricamente ha dejado ríos muertos, cordilleras deforestadas, ejércitos de desempleados, así como campesinos e indígenas sin tierras; así mismo, ha provocado comunidades en conflicto, enfermedades, violaciones de derechos humanos, obstrucción en los derechos de paso, entre otros problemas.

Ejemplos hay muchos: en Durango, ejidatarios de Otilón Montaño demandan el pago de cuarenta y tres millones de pesos por usufructo de sus tierras a la empresa Real de Oro por las actividades de su mina El Castillo (Maldonado, 2015); en Chicomuselo, Chiapas, el dirigente del Comité para la Promoción y Defensa de la Vida, Samuel Ruiz García, seña- 
laba que buscan protegerse de la extracción minera, que en su región cuenta con dieciséis concesiones (Chiapas Paralelo, 2013); en la localidad de Tetela, en la Sierra Norte de Puebla, sus habitantes se organizaron en un frente llamado "Tetela hacia el futuro" para defenderse de la explotación de oro que pretende realizar la empresa mexicana Frisco, propiedad de Carlos Slim (La Jornada de Oriente, 2013); en Cerro La Mira, municipio de Lázaro Cárdenas, Michoacán, cuatrocientas familias han sido afectadas por el desgajamiento del cerro La Cruz, por lo cual sus habitantes se organizaron en la asociación "Colonias Unidas de La Mira" para buscar una solución al problema (El Sol de Morelia, 2013).

Otras organizaciones que se han creado en el mismo tenor son "Medio Ambiente y Sociedad de Baja California Sur", contra el proyecto "Concordia"; "San Luis Ecológico" (San Luis Potosí) contra la Minera San Xavier; en Morelos, algunas contra del plan de la canadiense Esperanza Silver; en San José del Progreso, Oaxaca, una asociación opositora a la minera Cuzcatlán-Fortuna Silver; así como otras protestas, incluso ante el Senado de la república (Guillén, 2013b). En el ámbito internacional ocurre lo mismo: Colombia, Perú, Argentina, Brasil, entre otros, muestran gran activismo contra la minería (Radio Contagio, 2013).

Las empresas concesionarias mineras, a efecto de obtener la mayor ganancia, utilizan técnicas extractivas que permiten con rapidez y bajo costo procesar millones de toneladas de material mineralizado. ${ }^{18}$ Por ejemplo, sólo la minera Peña Colorada produce 8.5 millones de toneladas de mineral por año. El volumen y la técnica extractiva "a cielo abierto" traen como consecuencia impactos negativos al territorio,

18. Algunos de los principales impactos ecológicos que la explotación minera genera son salificación, secamiento y escasez de agua (esto por las enormes cantidades que requiere el proceso de extracción), liberación y migración de metales pesados, sedimentación en los ríos, aumento en la vulnerabilidad a la erosión eólica e hídrica, migración de cianuro altamente tóxico en aguas subterráneas y superficiales, etcétera. 
tanto socioambientales como sanitarios, económicos, políticos y culturales. ${ }^{19}$ Por ello, estas prácticas mineras han despertado un creciente rechazo social, particularmente entre los pobladores de las zonas directamente afectadas.

Está ampliamente documentado que para obtener una tonelada de metal se requieren millones de litros de agua. La mayor parte de los documentos no oficiales (es decir, diferentes a los de la SE) referidos a lo largo del presente artículo tratan sobre el consumo y contaminación del agua: autores como Alejandra Guillén, Alberto Osorio y Darcy Tetreault insisten en el tema y aportan diversos datos.

Por ejemplo, la minera Benito Juárez Peña Colorada emplea grandes cantidades de agua para transportar por ferroducto a presión el mineral rumbo a la peletizadora de Manzanillo (Guillén, 2009a; Osorio, 2013; Tetreault, 2007). Adicionalmente, los efectos por el acaparamiento del agua y la contaminación de fuentes superficiales y subterráneas se acentúan por el desmonte de bosque y aterramiento de la vegetación. La actividad minera colateralmente destroza las coberturas vegetales, algunas de gran valor por su endemismo o porque son especies en proceso de extinción.

Los impactos generados por la actividad minera, enfocados principalmente en el municipio de Cuautitlán, Jalisco, desde hace décadas han propiciado el descontento entre los habitantes con raíces ancestrales, quienes ven mermadas sus actividades agrícolas porque las tierras fértiles han sido afectadas por la actividad minera. Las comunidades nahuas "llevan años padeciendo el saqueo" por parte de empresas mineras y madereras (Revista Proceso, 2013).

19. La técnica de explotación denominada "a cielo abierto" implica la remoción de toneladas de tierra por gramos o fracciones de gramo de material recuperable; es un desarrollo viable gracias al uso de procesos químicos de flotación o lixiviación a través cianuro, mercurio u otros químicos altamente tóxicos. Estos procesos son la causa de daños irreversibles que provocan modificaciones substanciales a los territorios aledaños; contaminan y agotan los recursos hídricos, provocando envenenamiento $y$ escases de agua.

\section{4}


En reclamo por los saqueos, diversos grupos de ejidatarios han alzado la voz en defensa de sus tierras y recursos, pero no han trascendido hacia la voluntad de los tomadores de decisiones en este país. Gaudencio Mancilla, representante del Consejo de Mayores del pueblo de Ayotitlán, señaló que fue agredido por elementos de la Fiscalía General del estado de Jalisco, culpándolo de intentar crear una policía comunitaria; además, aseguró que fue detenido y golpeado por supuesta portación de arma prohibida. Alegó en su defensa que la arbitrariedad de que fue objeto se debe al "asunto de la minas", es decir, "por haber parado lo de las minas" (Pereira y Velazco, 2013). En últimas fechas, a Mancilla se le sentenció a tres años de prisión, habiéndole sido otorgada libertad bajo fianza (Ferrer, 2014).

En julio de 2013, se publicó una investigación periodística en la revista Proceso, donde se documentó que más de ciento cincuenta comuneros de Ayotitlán "detuvieron trabajos de Piedra Imán y otro de Cañada Verde, Cuautitlán [...] en la zona de conflicto limítrofe entre Jalisco y Colima" (Osorio, 2013). Sobre este particular, cabe señalar que las concesiones de las minas fueron promovidas y otorgadas desde el estado de Colima sobre territorio indígena nahua que se presume es jurisdicción jalisciense.

El abogado Oscar González Garí, representante de la Red Mexicana de Afectados por las Minas, señaló que en la zona existían varias empresas mineras como Peña Colorada, Minera del Norte, Minera de la Rosa, Gan-Bo y Minera Metalúrgica Tapalpa, que son los "principales responsables de la depredación en Cuautitlán [...] Cihuatlán, Villa Purificación y Tonaya -donde viven más de 62000 personas-" (Osorio, 2013).

Agregó que, conforme a las exigencias de las comunidades afectadas y los argumentos jurídicos planteados, fue procedente un amparo para que saliera Gan-Bo por "inva- 
dir y contaminar" propiedades ejidales de Tequesquitlán (Osorio, 2013).

De la misma forma, González Gari, en su calidad de representante legal, advirtió que

Gan-Bo es como una plaga, que sigue asolando al estado [...] al menos cinco municipios y [hay] varias empresas mineras que cuentan con dieciséis concesiones para la explotación de oro, plata, cobre, hierro y otros, para cuya extracción se utilizan procesos industriales muy contaminantes (Osorio, 2013).

Asimismo, sentenció que no faltará dónde vuelva a asentarse esta empresa transnacional y quién le ofrezca traspasar su concesión minera, como muchas que la Subdirección de Minas reparte como "caramelos", al grado que ya el $25 \%$ del territorio nacional está "hipotecado" a esta "plaga" de extranjeros "enamorados de la riqueza de nuestro subsuelo" (Osorio, 2013). En contraparte, los representantes de Gan-Bo argumentaron que con esa cancelación se cerró la fuente de trabajo de ciento cuarenta personas de la región (Osorio, 2013).

Por otro lado, en el mismo artículo se sugiere

investigar y sancionar al Consorcio Minero Benito Juárez Peña Colorada, S. A. de C. V., filial de las transnacionales Ternium-Ispat-Mittal Steele, que ocasionó -al parecer deliberadamente- la caída de tres cortinas de retención de desechos minerales tóxicos sobre chozas, tierras, árboles frutales y brechas de Puertecito de las Parotas, Mameycito y Los Potros, todas ellas rancherías nahuas cercanas a Ayotitlán (Osorio, 20I3).

Junto con el conflicto jurisdiccional, a manera de síntesis y en palabras de Jorge Ceja (2014, p. 8), podría decirse que

la comunidad indígena de Ayotitlán [...] ha tenido que enfrentar, por un lado, a la minera Peña Colorada, $y$, por el otro, al crimen organizado que, a la vista de todos, diariamente extrae de las tierras comunales decenas 
de camiones cargados con madera y hierro robado para embarcar el botín vía puerto de Manzanillo, Colima, con destino a China.

En lo que respecta particularmente a la franja fronteriza en disputa jurisdiccional (zona B), la localidad históricamente más afectada por la minería ha sido Las Pesadas, la cual está ubicada a un kilómetro aproximadamente del yacimiento en explotación El Pesar. Por esta razón, las más de siete decenas de pobladores, dada la cercanía de su hábitat, son las que sufren en forma más directa e intensa los daños derivados de la explotación minera: la contaminación de aguas y suelo; además, son afectados por el ruido y los "proyectiles" (rocas que caen cuando hay explosiones), que en ocasiones han herido físicamente a los habitantes.

De hecho, la instalación del conflicto jurisdiccional entre Jalisco y Colima tuvo como antecedente inmediato la recomendación que la Comisión Nacional de Derechos Humanos (CNDH) emitiera a ambos Gobiernos en septiembre de 1995, en el sentido de que arreglaran sus diferencias respecto a sus límites territoriales. Esta recomendación quedó identificada con el numeral 122/95, y se refería principalmente a las afectaciones de los derechos humanos que por la indefinición de límites sufrían los pobladores de Las Pesadas y El Platanar (ubicadas en lo que posteriormente se definió como "zona B" del conflicto).

Dicha recomendación hacía alusión a que los problemas por indefinición jurisdiccional estaban agravados por actos caciquiles y la actividad minera que se realizaba, mismos que impedían el libre tránsito y el acceso al agua, además de que se les despojaba de tierras a los pobladores y se les aterraban sus coamiles. ${ }^{20}$

20. "Cuamil", o "coamil", es la superficie que se cultiva durante las lluvias de temporal con tracción animal o de forma manual, y usualmente es una pequeña área de traspatio -o pedregosa o de ladera, como en este caso- en la que difícilmente podría usarse un tractor. 
Teniendo como referentes dicha recomendación y los antecedentes generados entre 1989-1992, cuando los Gobiernos de Colima y Jalisco convinieron nombrar comisiones de estudio e instalar mesas de negociación para llegar a un acuerdo amistoso en el tema de la indefinición jurisdiccional, ${ }^{21} \mathrm{y}$ ante la persistencia del conflicto, el Gobierno de Jalisco promovió en 1997 una controversia constitucional que fue admitida en enero de 1998, la cual, como se dijo antes, quedó instalada como "controversia constitucional 3/98".

Las localidades de Las Pesadas, Plan de Méndez y El Platanar constituyen las principales comunidades que han sostenido una lucha histórica por la defensa de sus recursos y su identidad como jaliscienses; ellas, además de su lucha por reivindicar identidades territoriales, han enfrentado la tala clandestina e inmoderada de sus bosques, y, desde mediados del siglo XX, los problemas provocados por las empresas mineras, que han degradado sus recursos de flora y fauna, contaminado el agua y dejado inservibles las tierras para sembrar, esto debido a la ocupación para la extracción de mineral y al depósito de material estéril que realizan las mineras en zonas de cultivo y también donde se solía obtener agua (ojos de agua), o donde se realizaba pastoreo, recolección de plantas y caza de animales.

Esta indefinición jurisdiccional ha dejado desprotegidos a los lugareños en relación con las empresas mineras y algunos actos caciquiles que lucran a partir de vacíos de poder o por el traslape del mismo. Al respecto, María Ruiz Roblada, habitante de la localidad de Las Pesadas, de noventa años de edad, señalaba:

2I. Los comisionados por parte de Jalisco convinieron elaborar una memoria de los trabajos realizados, misma que fue publicada como suplemento en el periódico El Informador, titulado "Límites entre Jalisco y Colima”, el martes 26 de febrero de 199I, en su página ocho. También se puede considerar parte de esa memoria la publicación Límites de Jalisco, de José María Muriá, en 1997, así como Límites territoriales, de Hirineo Martínez y Adelina Moreno. 
No tenemos agua. Antes había arroyitos aquí y allá, pero cuando llegaron las minas nos dejaron sin agua; ahora sólo hay un ojo de agua aquí cerquita, la traen con mangueras, pero el terrateniente a veces la retiene y duramos días sin tener con qué lavar un traste, entonces tenemos que bajar al ojo de agua arriesgándonos a que nos corra la gente de Figueroa (entrevista personal, 2012a).

Otra habitante de Las Pesadas, Verónica Monroy Rosales, se manifestaba en cuanto a la desatención del Gobierno, al decir que

hay mucho mineral, por eso los Gobiernos no nos atienden, sería mejor para nosotros ser [espacio] federal, para no tener problemas, porque al menos ya tendríamos agua. Por el problema de límites el pueblo no progresa, no tenemos a quién acudir porque nos mandan a un lado o a otro, además ya hay conflicto en el pueblo porque hay gente que quiere [pertenecer] a Colima y otros a Jalisco. Nuestro recibo de luz aparecía como "Jal.-Col." (entrevista personal, 20I2b).

En el mismo sentido, Celia Aguilar Roblada, habitante de Plan de Méndez, de sesenta y tres años de edad, decía que el agua del río Minatitlán está contaminada, lo que se evidencia en que no permite que se genere espuma cuando se usa para lavar, y que los animales se han enfermado y muerto cuando toman de esa agua (entrevista personal, 2012c).

Camila Valenzuela, habitante de El Platanar, no ha estado exenta de problemas derivados de la indefinición jurisdiccional. Al respecto, comentó que cuando hicieron la escuela y el kínder por Colima, Jalisco mandó al Ejército y se quedaron a acampar en los patios de la escuela para cuidar que Colima no siguiera con la obra. La gente tenía que dar de comer a los soldados lo poco que tenían (entrevista personal, 2012d).

En contraparte, algunos lugareños identifican acciones positivas derivadas de la explotación minera. Al respecto, 
Julián Sánchez Monroy, habitante de la localidad de Las Pesadas, dice que por su cuenta, habiendo trabajado un tiempo en la minera Peña Colorada, se vinculó con directivos que los apoyaron para terraplenar y emparejar la brecha de acceso a la localidad, además de poner piso a la pequeña capilla. Señaló que para emplearlos en las minas piden como requisito mínimo educación secundaria, y que "antes no daban trabajo a los de los alrededores, pero los del ejido se organizaron y ya están aceptando" (entrevista personal, 2011).

Los anteriores testimoniales respaldan las denuncias que han documentado diversos medios, de los cuales aquí también se han referido algunos. Por tanto, queda claro que no se están respetando los derechos de los lugareños en sus recursos, los derechos humanos para su mejor vivir, y que tampoco se está cumpliendo con algunos postulados fundamentales de la Ley General del Equilibrio Ecológico y la Protección al Ambiente (LGEEPA), ${ }^{22}$ la cual, entre otras cosas, en su artículo $1^{\circ}$, se refiere a la

preservación y restauración del equilibrio ecológico, así como a la protección al ambiente, en el territorio nacional y las zonas sobre las que la nación ejerce su soberanía y jurisdicción. Sus disposiciones son de orden público e interés social y tienen por objeto propiciar el desarrollo sustentable (Congreso de la Unión, 1988).

Para lograrlo, entre sus bases se establece lo siguiente: 1) garantizar el derecho de toda persona a vivir en un medio ambiente adecuado para su desarrollo, salud y bienestar; 2) la preservación y protección de la biodiversidad, así como el establecimiento y administración de las áreas naturales protegidas; y 3) la prevención y el control de la contaminación del aire, agua y suelo. 
Un ejemplo reciente sobre la cancelación de actividades mineras por el impacto ecológico negativo provocado fue la promovida por la comunidades nahuas del municipio de Cuautitlán de García Barragán, quienes lograron una resolución por parte de autoridades federales para que la empresa Gan-Bo dejara de operar, bajo el argumento principal de que la explotación minera se encontraba dentro de unidades de gestión ambiental (UGA) catalogadas como de alta fragilidad ecológica, con lo cual esa área tenía asignada una política territorial de conservación de su flora y fauna, con uso de suelo predominante agrícola, en compatibilidad con el desarrollo de vida silvestre, altamente restrictiva a actividades industriales y mineras.

Desde luego, resulta importante conocer con mayor detalle hasta qué punto la exploración y explotación minera perjudica la ecología y las organizaciones socioterritoriales, pero eso será tarea de otras investigaciones y de otras publicaciones. Aquí se han aportado algunos datos y planteado el problema, pero desde luego hace falta mucho por hacer en la temática y en particular sobre estos lugares. Como principio normativo y metodológico hay que regresar al artículo 28 de la Ley General de Equilibrio Ecológico y la Protección al Ambiente, el cual señala que la actividad minera se tiene que regular y por lo tanto se requiere previa autorización en materia de impacto ambiental.

\section{Conclusiones}

La actividad minera genera contrasentidos porque a nivel macro- crea buenos dividendos y está considerada como una actividad prioritaria para el desarrollo nacional, pero, en contraste, a nivel micro- resulta altamente nociva para el desarrollo socioeconómico de los habitantes de las cercanías donde se practica la actividad minera de mediana y gran escala. 
En este sentido, se debe crear conciencia para buscar alternativas que resulten más compatibles a los intereses de la nación frente a los intereses de los lugareños en zonas mineras, porque los costos ambientales y sociales, en general, son pagados por las comunidades campesinas e indígenas, cuyos medios de vida y salud son amenazados por la minería.

De los 1847 denuncios mineros en el estado de Jalisco de lotes titulados (trescientos tres cancelados), ochenta y uno están dentro de la zona aquí estudiada. Existen otros lotes mineros que aún no están titulados, pero operan clandestinamente tanto en la extracción como en la comercialización del mineral, lo cual agrava la situación en lugares como la frontera Cuautitlán-Minatitlán, donde predominantemente se siguen desarrollando por los lugareños las actividades agropecuarias, caza y recolección: "Desde 2008 en la región [...] Costa Sur se agudizó el robo de hierro para exportarlo a China por el puerto de Manzanillo" (Guillén, 2013a). De la misma manera, se ha mencionado que "los asiáticos se llevan hierro y maderas preciosas" (Guillén, 2013a y 2013b).

Estos modos de vida rural y campesina están siendo altamente alterados por la forma en que se otorgan las concesiones y la forma como se practica la actividad minera. En primer lugar, se afectan con la colocación de cercados en predios o lotes mineros que cortan caminos, se restringe el derecho de paso y se impide el acceso a lugares donde tradicionalmente se acudía a satisfacer alguna necesidad básica como el abasto de agua, la colecta de alimento, la siembra de coamiles, etc.

En segundo lugar, se padecen de afectaciones por contaminación de agua y suelo, deforestación, ruido, lanzamiento de proyectiles y demás efectos colaterales, lo cual no retribuye de manera equitativa en beneficios materiales o económicos para los lugareños, pues la mayor parte de las ganancias se traslada a lugares remotos. 
Se puede decir que en el lugar de estudio viven dos mundos: el de los lugareños y el de las mineras, que evidentemente se pueden integrar en uno por diversas vías: una de ellas es el conflicto y otra el paisaje. El primero ya se ha documentado aquí ampliamente. Sobre el segundo sólo se dirá que es altamente contrastante un paisaje rural, con predominancia de vida silvestre, con las enclaves mineras que parecen de otro lugar, incluso de otros mundos, como cráteres lunares; "paisajes lunares" que aumentan con rapidez en la zona. Algo se tendrá que hacer para mitigar los impactos: las tendencias socioterritoriales y ecológicas deberán cambiar para aspirar a un desarrollo sustentable, sostenible y con justicia social.

Dado que aproximadamente el 90\% de esta superficie está concesionada, los lugareños están aprisionados en sus localidades; algunos incluso tienen su vivienda dentro de los lotes que han sido concesionados, lo que deja a sus habitantes con muy pocas opciones para subsistir y con nulas posibilidades para desarrollarse.

La frontera Cuautitlán-Minatitlán (antes El Mamey) significa el encuentro de dos proyectos, el choque de culturas: desde Jalisco, por ese rumbo se proyecta la cultura indígena, sustentada en la vida rural y campesina, mientras que desde Colima se proyecta la cultura mestiza sustentada en una emergente actividad minera. Esto, por supuesto, genera tensión en la frontera y conflicto social entre los dos proyectos, pero también entre los intereses locales respecto a los intereses empresariales provenientes del exterior.

La actividad minera ha generado riqueza en algunos cuantos, pero pobreza y desgracia para la mayoría de los habitantes ancestrales. ¿Qué hacer para atenuar las desproporciones y los efectos nocivos? Desde esta "trinchera", la académica, corresponde seguir documentado la situación y tomar compromiso en el sentido de que otro mundo es posible. 
México es considerado entre los cuatro primeros países de América Latina (junto con Perú, Chile y Argentina) con mayor número de conflictos socioambientales provocados por la explotación minera. Sus impactos, entre otros, son contaminación, restricción o escasez de agua, antidemocracia (no se hace consulta previa a las comunidades de habitantes), disputas territoriales, desplazamiento de pueblos originarios, cambios de uso de suelo y violaciones de derechos humanos, pero también se proyectan conflictos por la inequitativa repartición de rentas e ingresos tributarios provenientes de las actividades mineras (González, 2013). De ahí el clamor de las comunidades al señalar que "la riqueza de nuestras tierras ha sido la desgracia de nuestra historia" (El Informador, 1998, p. 25).

Bibliografía

Acosta Córdova, C. (09 de septiembre de 2013). "Ofusca a empresarios reforma hacendaria de Peña". Proceso. Recuperado de: http://www.proceso.com. $m x / ? p=352361$

Arenas, E. (II de noviembre de 20I2). "Exigen a la mina Peña Colorada responda por ecocidio que causó”. El Occidental. Recuperado de: http://cronicadesociales. org/20 I 2/ I I/ I /exigen-a-la-mina-pena-colorada-responda-por-ecocidio-que-causo/\#more-80283

Castro, G. (2013). La minería y consecuencias en México. San Cristóbal de las Casas: Otros Mundos, A. C./Red Mexicana de Afectados por la Minería/M4. Recuperado de: http://www.conflictosmineros.net/contenidos/23mexico/I I 768-la-mineria-y-consecuencias-en-mexico

Ceja, J. (20/4). "Extractivismo minero, globalización neoliberal y resistencia socio-ambiental en México". Contextualizaciones latinoamericanas, 6(I I). Recuperado de: http//www.contextualizacioneslatinoamericanas.com. $\mathrm{mx} / \mathrm{pdf} /$ extractivismominero,globalizaciónneoliberaly resistenciassocioambientalesenmexico_I I.pdf 
Chiapas Paralelo (08 de octubre de 20 I3). "Abuelo de goberBibliografía nador de Chiapas amenaza a lugareños que se oponen a explotación minera". Observatorio de Conflictos Mineros de América Latina (OCMAL). Recuperado de: http://www. conflictosmineros.net/contenidos/23-mexico/I5434abuelo-de-gobernador-de-chiapas-amenaza-a-lugarenos-que-se-oponen-a-explotacion-mineraa

Coll Hurtado, A., y Sánchez Salazar, M. T. (1999). "México. Globalización y espacios mineros”. Baética. Estudios de arte, geografia e historia, (2I), 35-56.

Congreso de la Unión (28 de enero de 1988). Ley General del Equilibrio Ecológico y Protección al Ambiente (última reforma el 7 de diciembre de 2005). Recuperado de: http://www.diputados.gob.mx/LeyesBiblio/ pdf/I48_090I I5.pdf

Delgado, B. (03 de mayo de 20I3). Entrevista personal con Hirineo Martínez Barragán. Guadalajara, Jalisco, México.

Diario de los Debates (26 de diciembre de 1939). Iniciativa de Ley Reglamentaria del Artículo 27 Constitucional en materia de petróleo. Exposición de motivos. México: Cámara de Diputados del Congreso de los Estados Unidos Mexicanos.

Diario Oficial de la Federación (26 de julio de 1992). Ley Minera (última reforma el 26 de julio de 2006). México: Cámara de Diputados del H. Congreso de la Unión.

Dirección General de Desarrollo Minero (s/f). Sistema Integral de Economía de Minerales (SINEM), Secretaría de Economía. Recuperado de: http://portalweb.sgm.gob. $\mathrm{mx} /$ economia/es/mineria-en-mexico/empresas-mineras/ 337-empresas-con-proyectos-mineros-en-mexico.html Esquivel, E. (08 de mayo de 2013). "La minería en México, un negocio para pocos". SDP Noticias. Recuperado de: http://www.sdpnoticias.com/columnas/20 I 3/05/08/lamineria-en-mexico-un-negocio-para-pocos 
Bibliografía
Estrada, J., y Martín, R. (cond.) (09 de mayo de 20I3). Cosa pública (entrevista radiofónica a Salvador Díaz, ejidatario de Tequesquitlán, municipio de Cuautitlán de García Barragán, Jalisco, sobre problema de minería en la zona). Guadalajara: Radio Metrópoli.

El Informador (16 de febrero de 1998). "Como rehenes los habitantes de los límites con Colima”, p. 25.

El Sol de Morelia (30 septiembre 2013). "Explotación de mineral y lluvias causan deslaves". Observatorio de Conflictos Mineros de América Latina (OCMAL). Recuperado de: http://www.conflictosmineros.net/contenidos/23mexico/ I5406-explotacion-de-mineral-y-lluvias-causandeslaves

Ferrer, M. (29 de mayo de 20I3). "Habitantes del sur de Jalisco demandan a minera china". La Jornada Jalisco. Recuperado de: www.lajornadajalisco.com. $\mathrm{mx} / 20 \mathrm{I} 3 / 05 / 29 /$ habitantes-del-sur-de-jalisco-demandan-a-minera-china/

(08 de enero de 2014). "Juez federal dicta sentencia contra Gaudencio Mancilla por portación de arma". La Jornada Jalisco. Recuperado de: http://www. lajornadajalisco.com.mx/20 I 4/0 I/08/juez-federal-dictasentencia-a-lider-nahua-por-portacion-de-arma-de-usoexclusivo-del-ejercito/

García, I. (3I de octubre de 20I3). "El Poder Legislativo aprueba los nuevos impuestos para 2014". CNN México. Recuperado de: http://mexico.cnn.com/ nacional/20 I 3/I0/3 I/el-poder-legislativo-aprueba-losnuevos-impuestos-para-20I 4

García, M., González, S., Sánchez, A., y Verduzco, B. (1998). Descentralización e iniciativas locales de desarrollo. México: Universidad de Guadalajara/UCLA Programación México, Juan Pablos.

González, S. (20 de octubre de 2013). "México, uno de los países de AL con más problemas con mineras: CEPAL”. 
NSS Oaxaca. Recuperado de: http://www.nssoaxaca. Bibliografía com/nacional/I-general/64 I60-mexico-uno-de-lospaises-de-al-con-mas-problemas-con-mineras-cepal Guillén, A. (14 de octubre de 2009a). "Hierro de Jalisco se va a China”. El Informador. Recuperado de: http://www. informador.com.mx/jalisco/2009//45544/6/hierro-dejalisco-se-va-a-china.htm

(I6 de octubre de 2009b). "Minas amenaza para Manantlán”. El Informador. Recuperado de: http://www. informador.com.mx/jalisco/2009//46/22/6/minasamenaza-paramanantlan.htm

(22 de agosto de 2013a). "Fiscalía de Jalisco tiene detenido a líder nahua de Ayotitlán”. Proceso. Recuperado de: http://www.proceso.com.mx/?p=350732

(07 de septiembre de 20I3b). "Mineras siembran el terror en Cuautitlán”. Proceso. Recuperado de: http:// www.proceso.com.mx/?p=352। 4 I

INEGI (200I). Carta topográfica I:50 000. Clave EI3B33 (Minatitlán). Archivos digitales de la Subsecretaría de Minas, Guadalajara, México.

(20I3). Minería. Recuperado de: http://www.cuentame.inegi.org.mx/economia/secundario/mineria/

Instituto Nacional de Ecología (s/f). Importancia de la minería en México. Recuperado de: http://www2.inecc.gob.mx/ publicaciones/libros/I6/parte3_I2.html

Koch, J. (s/f). "Consecuencias de la minería sobre el medio ambiente", en, El libro del oro (s/p). Recuperado de: http://www.eumed.net/libros-gratis/2009c/568/DE\%20 LA\%20MINERIA\%20SOBRE\%20EL\%20MEDIO\%20 AMBIENTE.htm

Lagos, G. (ed.) (2005). Minería y Desarrollo. Foro en Economía de Minerales, vol. III. Chile: Ediciones Universidad Católica de Chile.

La Jornada de Oriente (08 de octubre de 2013). “Desde Tetela inician creación de un Frente Nacional contra las Mine- 
ras”. Observatorio de Conflictos Mineros de América Latina (OCMAL). Recuperado de: http://www.conflictosmineros. net/contenidos/23-mexico/I5435-desde-tetela-iniciancreacion-de-un-frente-nacional-contra-las-mineras Llano, M. (I 9 de julio de 20|4). "Cartografía minera y acceso a la información: ¿qué sabemos de lo que no sabemos?". La Jornada del Campo. Recuperado de: www.jornada. unam.mx/20l4/07/19/cam-minera.html

Maldonado, S. (22 de octubre de 20I5). "Ejidatarios toman mina de oro en San Juan del Río Durango". La Jornada Durango. Recuperado de: http://www.jornada.unam. $\mathrm{mx} / 20 \mathrm{I}$ / I0/22/politica/020n I pol

Martínez Barragán, H. (20II). La geopolítica del diferendo territorial entre entidades federadas. El caso de Cihuatlán Jalisco vs. Manzanillo Colima. 1998-20IO (tesis doctoral inédita). Universidad de Guadalajara: México.

- y Moreno Cervantes, A. (200 I). Límites territoriales. La frontera Jalisco-Colima. Guadalajara: Gobierno del estado de Jalisco.

Mendoza, R. (3I de diciembre de 20I3). "Entregaron la mitad de México a mineras". Observatorio de Conflictos Mineros de América Latina (OCMAL). Recuperado de: http://www.conflictosmineros.net/contenidos/23//6045 Noticias Terra (II de noviembre de 20I3). "Guatemala: 99\% de comunidad se opone a minería". Recuperado de: http://noticias.terra.com.mx/mundo/ america-latina/guatemala-99-de-comunidad-se-oponea-mineria,a3527df4ace324 I OVgnCLD2000000dc6eb0aRCRD.html

OCMAL (I3 de mayo de 20I3). "Tequesquitlán se opone a minera china Gan-Bo". Recuperado de: http://basedatos.conflictosmineros.net/ocmal_ $\mathrm{db} /$ ?page $=$ conflicto\&id $=717$ 
Osorio, A. (20 de julio de 20I3). "Gan-Bo se repliega, pero Bibliografía no se va". Proceso. Recuperado de: http://www.proceso. com.mx/?p=347903

Pereira, D., y Velazco, A. (24 de agosto de 2013). "La policía comunitaria es pretexto, es asunto de minas: Gaudencio Mancilla”. Crónica de Sociales. Recuperado de: http://cronicadesociales.org/20 I/08/24/lo-de-lapolicia-comunitaria-es-pretexto-es-asunto-de-minasgaudencio-mancilla/

Radio Contagio (07 de octubre de 2013). "Empresa Cerro Matoso contamina las aguas y afecta a 946 familias de la comunidad Zenú”. Observatorio de Conflictos Mineros de América Latina (OCMAL). Recuperado de: http://www. conflictosmineros.net/contenidos/23-mexico/I5426empresa-cerro-matoso-contamina-las-aguas-y-afectaa-946-familias-de-la-comunidad-zenu

Revista Proceso (30 de septiembre de 2013). "Lanzan campaña contra la 'megaminería tóxica”'. Observatorio de Conflictos Mineros de América Latina (OCMAL). Recuperado de: http://www.conflictosmineros.net/ contenidos/23-mexico/I 5404-lanzan-campana-contrala-megamineria-toxica

Secretaría de Economía (20|3a). Anuario Estadístico de la Minería Mexicana 20 I 2. México: Coordinación General de Minería, Servicio Geológico Mexicano.

- (20I3b). Empresas con proyectos mineros en México. Recuperado de: http://portalweb.sgm.gob.mx/economia/es/mineria-en-mexico/empresas-mineras/337empresas-con-proyectos-mineros-en-mexico.html

Taddei, E., Seoane, J., y Algranati, C. (20I I). Minería transnacional y resistencias sociales en África y América Latina. Ecuador: Grupo de Estudios sobre América Latina y el Caribe (GEAL). Recuperado de: http://www.extractivismo.com/documentos/ MineraiTransnacionalResistenciasAfricaALatr.pdf 
Bibliografía

Tetreault, D. (2007). Los proyectos de abajo para superar la pobreza y la degradación ambiental en dos comunidades del México rural: Ayotitlán y la Ciénega, Jalisco, octubre de 2007. México: Centro Universitario de la Ciénega, Universidad de Guadalajara.

- (20/2). "La minería mexicana en el contexto internacional". Observatorio del desarrollo, I(3), I8-20. Recuperado de: http://estudiosdeldesarrollo.net/observatorio/ob3/5.pdf

(20I3). "La lucha en torno a la minería en Manantlán”. Sociedad y Ambiente, I (2), 47-74. Recuperado de: http://revistas.ecosur.mx/ecofronteras/index.php/sya/ article/view/I 5

Urzúa Soto, S. (abril de 20I I). Entrevista personal realizada a Julián Sánchez Monroy. Las Pesadas, Colima-Jalisco. (abril de 2012a). Entrevistada personal realizada a María Ruiz Roblada. Las pesadas, Colima-Jalisco.

— (abril de 20I2b). Entrevista personal realizada a Verónica Monroy Rosales. Las Pesadas, Colima-Jalisco. (abril de 20I2c). Entrevista personal realizada a Celia Aguilar Robledo. Plan de Méndez, Colima-Jalisco. _ (abril de 2012d). Entrevista personal realizada a Camila Valenzuela. El Platanar, Colima-Jalisco.

(20I3). Gestión para el desarrollo en zona de indefinición jurisdiccional. El caso de tres localidades rurales en la frontera Jalisco-Colima, 1998-2010 (tesis de maestría inédita). Universidad de Guadalajara: México. 